\title{
CORRECTION
}

Xiaozhe ZHAO, Desheng WU

\section{CORRECTION to: Special issue: Decision, risk analytics and data intelligence}

(C) Higher Education Press 2020

\section{Correction to: Frontiers of Engineering Management https://doi.org/10.1007/s42524-020-0114-4}

In the original publication of the article, there is unfortunately one mistake in the authors' affiliations. Prof. Xiaozhe ZHAO's affiliation should be: Faculty of Management and Economics, Dalian University of Technology, Dalian 116024, China.

We would like to apologize to the authors and the readers for any inconvenience it may have caused.

The online version of the original article can be found at https://doi.org/10.1007/s42524-020-0114-4 